\title{
Effects of Using Diesel Particulate Filter and Diesel Oxidation Catalyst with Exhaust Gas Recirculation on the Performance of Compression Ignition Engine Fuelled with Diesel- Di Ethyl Ether Blend
}

\author{
Nagaraj R. Banapurmath ${ }^{1 *}$, K. S. Nagaprasad ${ }^{2}$, D. Madhu ${ }^{3}$, Sanjeevkumar V. Khandal ${ }^{1}$ \\ ${ }^{1}$ B.V.B. College of Engineering and Technology, KLE Tecbnological University, Hubballi, Karnataka, INDIA \\ ${ }^{2} K$. S. Institute of Technology, Bangalore, INDIA \\ ${ }^{3}$ Government Engineering College, Ramanagaram, INDIA
}

*Corresponding Author: nrbanapurmath@gmail.com

Citation: Banapurmath, N. R., Nagaprasad, K. S., Madhu, D. and Khandal, S. V. (2018). Effects of Using Diesel Particulate Filter and Diesel Oxidation Catalyst with Exhaust Gas Recirculation on the Performance of Compression Ignition Engine Fuelled with Diesel- Di Ethyl Ether Blend. European Journal of Sustainable Development Research, 2(3), 30. https://doi.org/10.20897/ejosdr/87153

Published: July 9, 2018

\begin{abstract}
In the present work, a single cylinder diesel engine was suitably modified to operate on diesel, diesel and diethyl ether (DEE) in blended form in which percentage of diethyl ether in diesel blends was varied from 5 to $20 \%$ in steps of $5 \%$. Further the effects of exhaust gas recirculation (EGR) on the performance of diesel engine fueled with alcohol and diesel blended fuels were studied. The pre-and post-combustion methods were adopted to study the performance of the modified diesel engine. Post combustion analysis involved use of emission control devices like Diesel Particulate Filter (DPF) and Diesel Oxidation Catalyst (DOC) combination for effective control of unburned hydrocarbon (UBHC) and particulate matter (PM) respectively. From the study it was observed that the engine was consistent in its operation throughout the experimental investigations when operated on selected fuel combinations. Based on the comprehensive experimental investigations carried out the following conclusions have been derived. The brake thermal efficiency (BTE) increased with increased injection of DEE and highest BTE was found to be $29.25 \%$ for $80 \%$ loading condition using 20\% DEE and without EGR. In-cylinder pressure and heat release profiles showed delayed combustion for DEE blends compared to diesel and the same was more pronounced with higher DEE blends. Shorter combustion duration was observed with DEE compared to diesel. Increased smoke and UBHC emissions were observed for increased EGR induction for all operating conditions while the oxides of nitrogen (NOx) emission decreased. For 20\% DEE fuel operation adopted along with DPF, smoke emissions reduced by $75 \%$. It is observed that, adopting DPF, NOx emission reduced by $10 \%$; while adopting DOC, NOx emission reduced by 6\%. At 80\% load optimum conditions for the modified diesel engine operation with selected fuel combinations were observed for $20 \%$ diethyl ether/diesel ratio, and $20 \%$ exhaust gas recirculation rate along with both DOF and DOC respectively.
\end{abstract}

Keywords: Di-Ethyl ether, diesel particulate filter, diesel oxidation catalyst, performance

\section{INTRODUCTION}

Diesel engines are durable, economical and therefore they are an important power source in farming and industrial equipments. However, the problems with them being their higher emissions. Therefore, all researchers should chant the statement "Research makes diesel engine greener". 

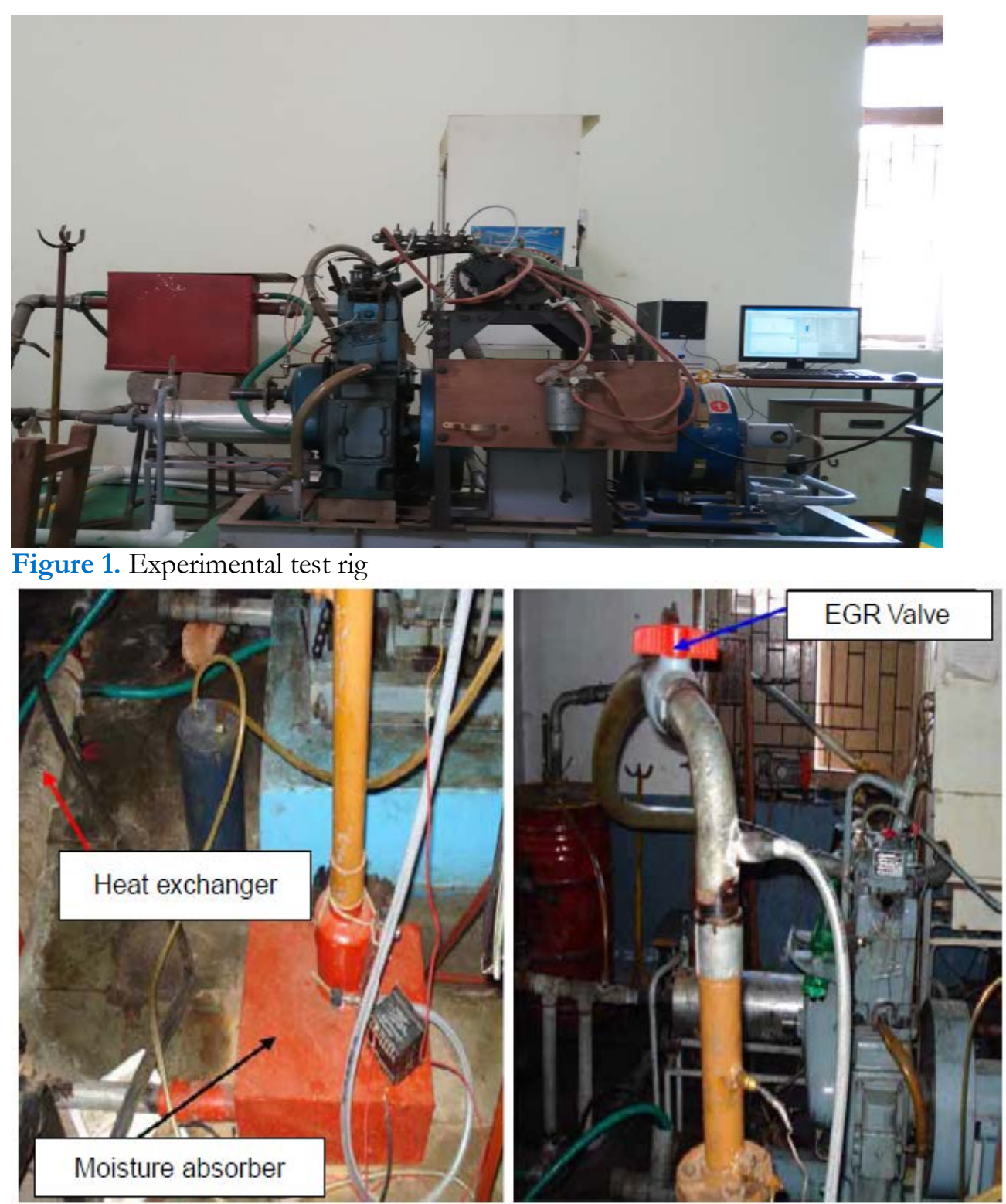

Figure 2. Exhaust gas recirculation arrangement

Re-circulating the exhaust gas reduced oxides of nitrogen $\left(\mathrm{NO}_{\mathrm{x}}\right.$, but increased smoke emission, hence there is a trade-off between $\mathrm{NO}_{\mathrm{x}}$ and smoke emission (Agrawal et al., 2004). The experiments were conducted using different injection timing (IT) and exhaust gas recirculation (EGR) to have tradeoff between NOx and smoke (Kouremenos et al., 2001). Potential of blending DEE with diesel fuel in different proportion (5\% 10\%, 15\% and 20\%) have been done. Retardation of IT and EGR are yieled reduced the NOx emissions (Mallikarjun et al., 2013). Significant improvements in all emissions with higher thermal efficiency were realized with the oxygenates besides engine noise reduction (Miyamoto et al., 1997). With growing concerns about NOx and particulate matter (PM) emissions from diesel engines, discussed the combination of a diesel particle filter system (DPF) with EGR was used to control of NOx, particulate matter (PM), CO and HC from diesel engines (Chatterjee et al., 2003). Aftertreatment system developed simultaneously reduced PM and NOx by $80 \%$ (Nakatani et al., 2002).

From the review of the literatures, it has been noticed that among the various techniques available to reduce NOx, the EGR is most essential to meet Euro standards.Use of oxygenated fuels like di methyl ether, di ethyl ether are done to enhance the performance. Hence, the present research work is focused on reduction of NOx and smoke emissions in diesel engines also to enhance the brake thermal efficiency (BTE).

The objectives of work are:

(1) To conduct experiments on existing diesel engine using DEE as additive blended fuels.

(2) To conduct performance test on existing diesel engine having optimized DEE/ Diesel ratio with EGR and study the emission reduction with EGR and after treatment devices.

(3) To establish test facilities for conducting experimental investigation of diesel engine with manifold injection for DEE at different timings and duration. 
Table 1. Specification of Engine

\begin{tabular}{|c|c|c|c|c|}
\hline \multirow{2}{*}{$\begin{array}{l}\text { Make and Model } \\
\text { Engine type }\end{array}$} & & \multicolumn{3}{|l|}{ Kirloskar, TV1 } \\
\hline & & \multicolumn{3}{|c|}{ Single cylinder, four stroke, water cooled, direct injection, diesel engine } \\
\hline Orientation & & \multicolumn{3}{|c|}{ Vertical } \\
\hline Ignition System & & \multicolumn{3}{|l|}{ Compression Ignition } \\
\hline Bore X Stroke & & \multicolumn{3}{|l|}{$87.5 \mathrm{~mm}$ X $110 \mathrm{~mm}$} \\
\hline Displacement Volume & & \multicolumn{3}{|l|}{$660 \mathrm{cc}$} \\
\hline Compression Ratio & & \multicolumn{3}{|l|}{$17: 5: 1$} \\
\hline Arrangement of valves & & \multicolumn{3}{|l|}{ Overhead } \\
\hline Combustion Chamber & & \multicolumn{3}{|l|}{ Open Chamber (Direct Injection) } \\
\hline Rated Power & & \multicolumn{3}{|l|}{$5.2 \mathrm{~kW}(7 \mathrm{HP}) @ 1500 \mathrm{rpm}$} \\
\hline Cooling Medium & & \multicolumn{3}{|l|}{ Water cooled } \\
\hline \multicolumn{5}{|l|}{ Air measurement manometer } \\
\hline Made & & \multicolumn{3}{|l|}{ MX 201} \\
\hline Type & & \multicolumn{3}{|l|}{ U-type } \\
\hline Range & & \multicolumn{3}{|l|}{$100-0-100 \mathrm{~mm}$} \\
\hline \multicolumn{5}{|l|}{ Eddy current dynamometer } \\
\hline Model & & \multicolumn{3}{|l|}{ AG-10 } \\
\hline Type & & \multicolumn{3}{|l|}{ Eddy current } \\
\hline Maximum & & \multicolumn{3}{|l|}{7.5 KW@1500-3000 rpm } \\
\hline Flow & & \multicolumn{3}{|l|}{ Must flow through dynamometer } \\
\hline Dynamometer arm length & & \multicolumn{3}{|l|}{$0.180 \mathrm{~m}$} \\
\hline Fuel measuring range & & \multicolumn{3}{|l|}{$0-50 \mathrm{ml}$} \\
\hline \multicolumn{5}{|c|}{ Table 2. Specification of Engine } \\
\hline Ratios & Diesel & $10 \%$ DEE & 15\% DEE & $20 \%$ DEE \\
\hline Specific Gravity (gm/cc) & 0.77 & 0.822 & 0.846 & 0.8806 \\
\hline Viscocity & 2.61 & 1.90 & 1.70 & 1.24 \\
\hline Calorific value $(\mathrm{kJ} / \mathrm{kg})$ & 43000 & 43860 & 44640 & 45041 \\
\hline
\end{tabular}

\section{EXPERIMENTAL SET UP AND METHODOLOGY}

Experimentations were done on a diesel engine developing $5.2 \mathrm{~kW}$ at $1500 \mathrm{rev} / \mathrm{min}$. The specification of diesel engine is as given in the Table 1. The speed of engine was regulated with the help of centrifugal governor. Push rods in engine with hemispherical combustion chamber were used to operate overhead valves. The water circulating through cylinder head and jackets on the engine was used to accomplish the cooling of the engine. The pressure in engine cylinder was measured with cylinder head mounted piezoelectric pressure transducer. The engine had a mechanical fuel injection system. The injector pressure is $205 \mathrm{bar}$, and static fuel IT is $23^{\circ}$ BTDC. Figure 1 shows the diesel engine test rig. EGR arrangement shown in Figure 2 was used to control NOx with varied flow rates. DPF and diesel oxidation catalyst (DOC) is placed in the exhaust pipe line of the engine. Figure 3 and Figure 4 shows the photograph of DPF and DOC used in the test runs. The diesel and DEE used in test runs had the property values as shown in Table 2 . The HRR was calculated using the procedure followed in literature (Hayes et al., 1986; Hohenberg, 1979).

\section{Preparation of Di Ethyl Ether Blends}

The respective blends of DEE with diesel in varied percentage of $5 \%$ to $20 \%$ in steps of $5 \%$ were prepared and for this $1000 \mathrm{ml}$ measuring jar, $10 \mathrm{ml}$ graduated test tube, container and the mechanical stirrer were used to prepare respective blends.

Following method was adopted for the blend preparation.

(1) The measuring jar and graduated test tube were thoroughly washed and cleaned dry.

(2) Required quantity of diesel was taken in the measuring jar and based on the requirement 50,100,150 and $200 \mathrm{ml}$ of DEE was added to it.

(3) The mixture in the container was thoroughly stirred for about 10-15 minutes by mechanical stirrer to obtain proper blending.

(4) $20 \mathrm{ml}$ of ethyl acetate was poured as an additive so as to prevent the interfacial tension between DEE and diesel. 


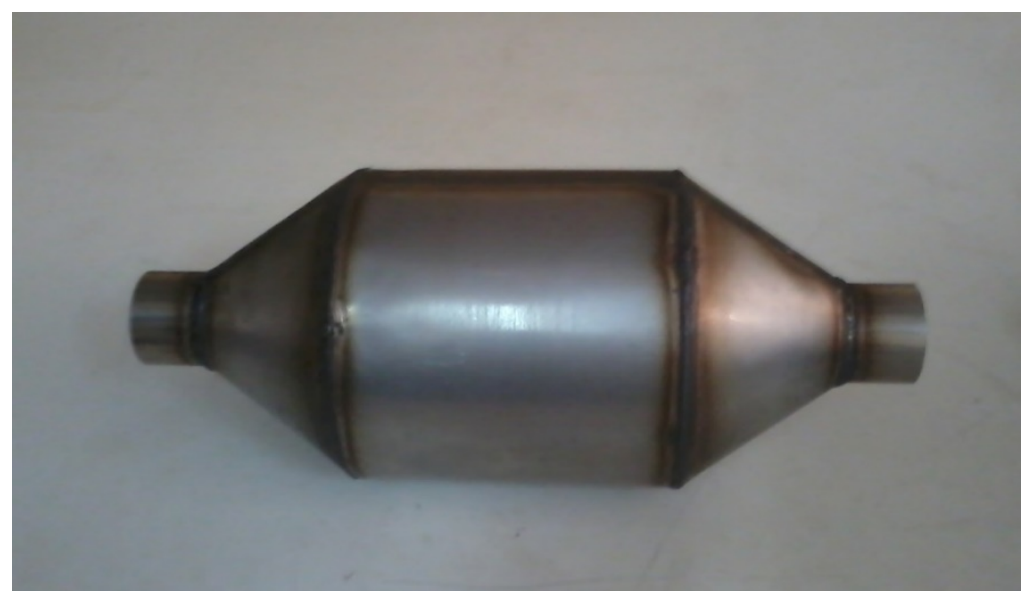

Figure 3. Photograph of Diesel Particulate Filter

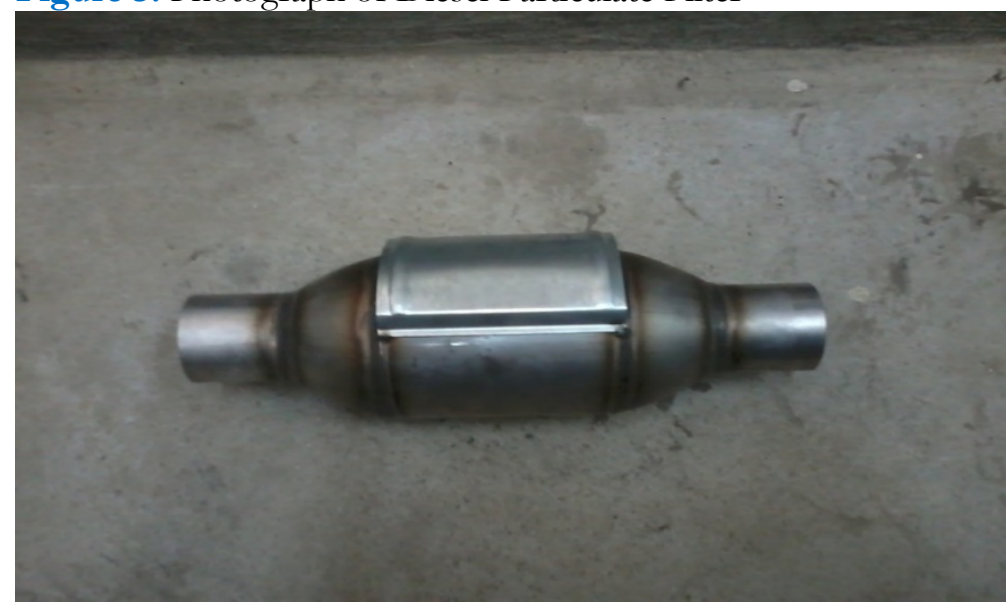

Figure 4. Photograph of Diesel Oxidation Catalyst

\section{RESULTS AND DISCUSSIONS}

This section explains the performance of the diesel engine operated on diesel engine at different load by varying the percentage of DEE as $5 \%, 10 \%, 15 \%$ and $20 \%$ by volume respectively. Also results of experiments conducted on 20\% DEE/ diesel blends at two loads respectively at fixed EGR rate of 20\%, DPF and DOC were discussed.

\section{erformance Characteristics}

\section{Brake Thermal Efficiency}

Figure 5 visualizes the variation of efficiency at different loads when the engine is supplied with $0,5,10,15$ and $20 \%$ volume of DEE. The efficiency has increased with increase in load (up to $80 \%$ ) for all the volume of DEE. BTE is found to be increasing by injecting the diethyl ether. The reason is that di-ethyl ether which is added as an additive supply as an extra oxygen molecule to the fuel for burning. Higher oxygen content led to better combustion and hence better BTE. Higher cetane number of DEE could also be a reason for better BTE. The highest BTE was found to $29.25 \%$ for $80 \%$ load condition using $20 \%$ DEE and without EGR.

BTE at $80 \%$ loads when the engine injected with $20 \%$ DEE with $20 \%$ EGR, using DPF and DOC is shown in Figure 6 BTE decreased when EGR is introduced. At $80 \%$ load, the engine has highest BTE of $29.25 \%$ without EGR and with $20 \%$ DEE.

\section{Emission Characteristics}

\section{Smoke Emissions}

The variation of Smoke emissions at different loads when the engine is supplied with $0 \%, 5 \%, 10 \%, 15 \%$ and $20 \%$ volume of DEE is as shown in Figure 7. Smoke is reduced with increase in blend of DEE. This reduction benefit is due to the presence of oxygen content in the DEE which enables normal combustion. Higher cetane number and lower auto ignition temperature of DEE could also be a reason for lower smoke. Additionally, smoke emissions are inhibited by the high volatility of diethyl ether. At $80 \%$ load, the smoke emission was found to be $60 \mathrm{HSU}$ and $50 \mathrm{HSU}$ for $0 \%$ and $20 \%$ DEE respectively. 


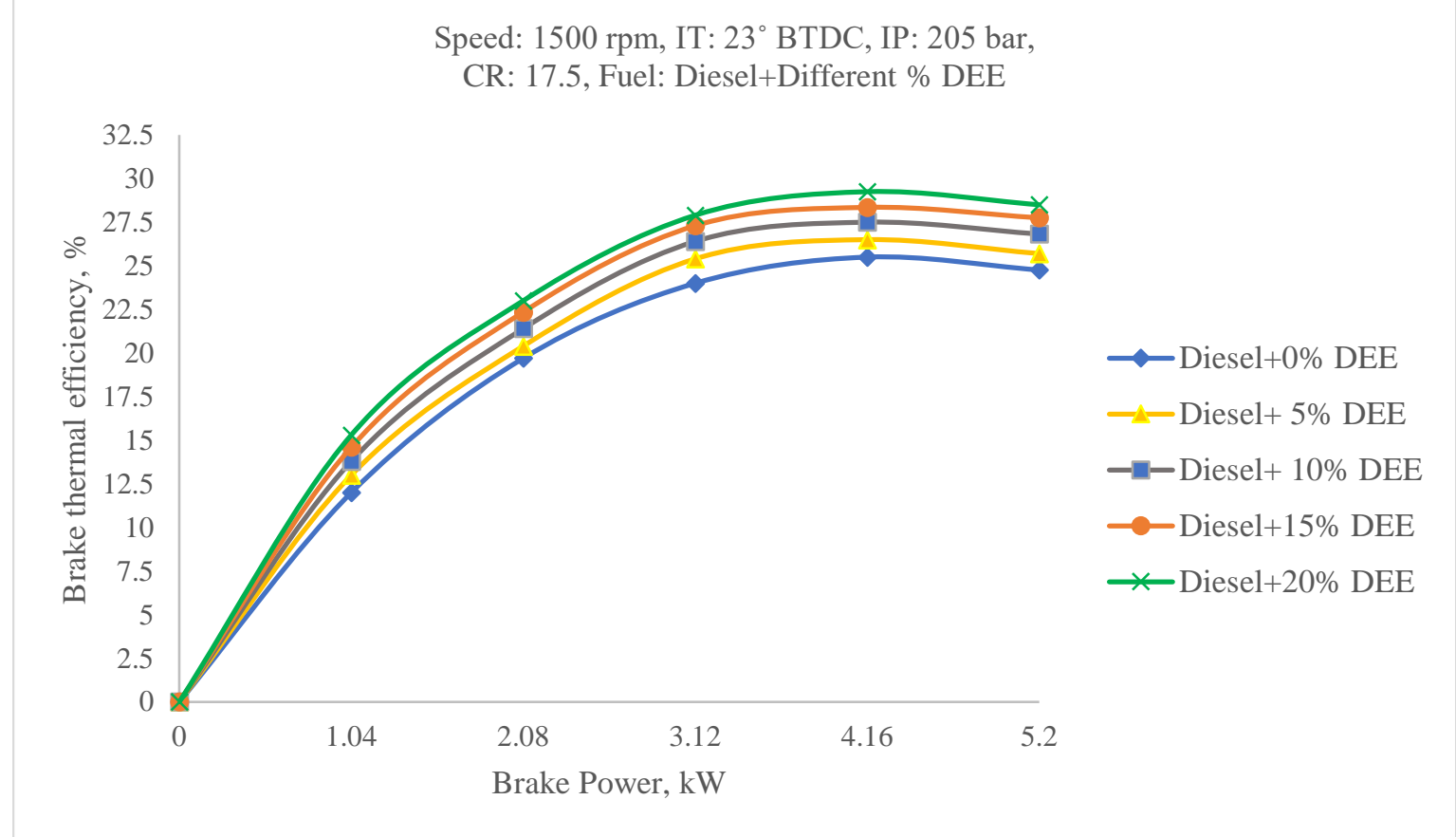

Figure 5. Effect of DEE on BTE

Speed: $1500 \mathrm{rpm}, \mathrm{IT}: 23^{\circ}$ BTDC, IP: 205 bar, CR: 17.5, Fuel: 20\% DEE

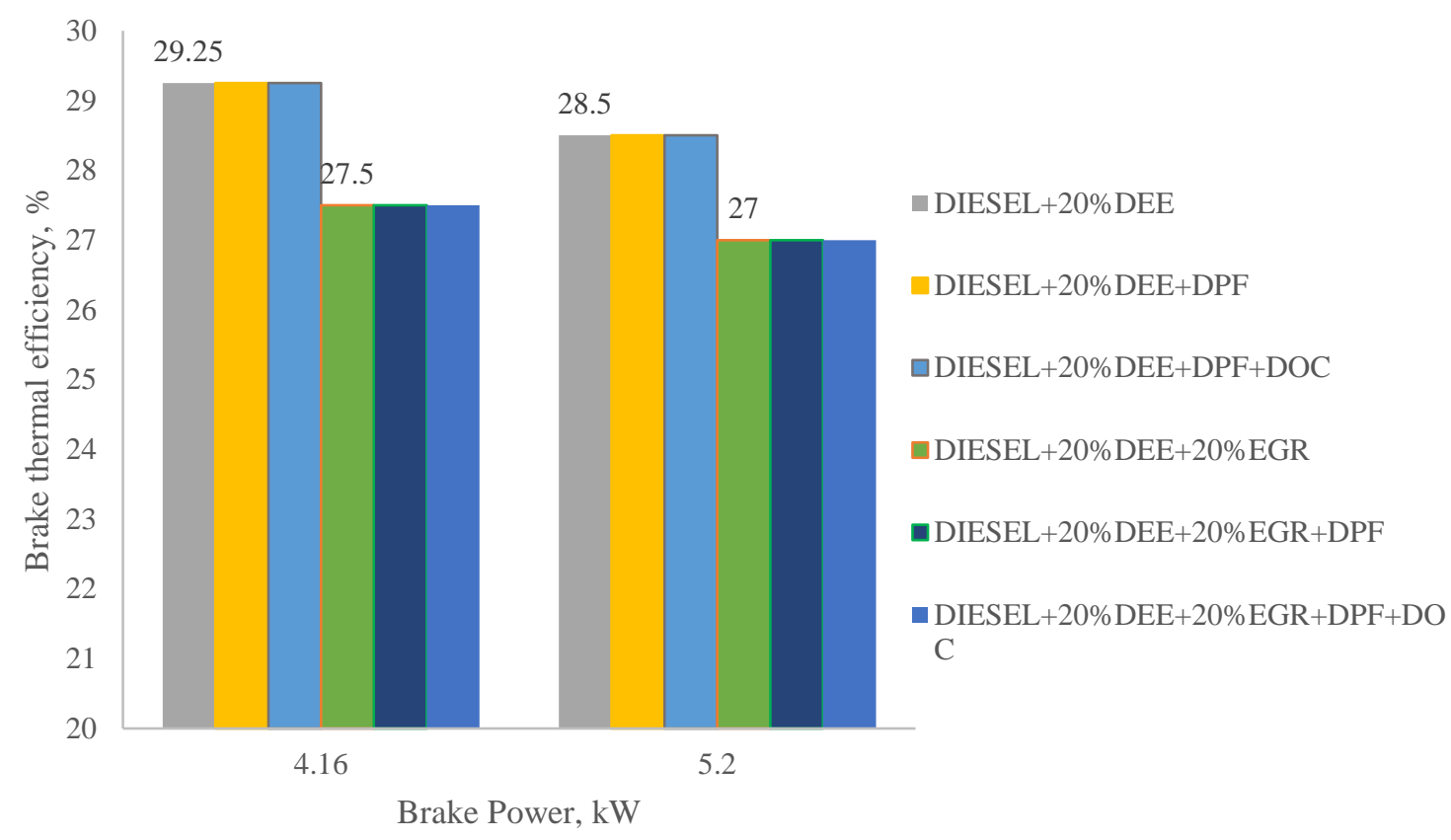

Figure 6. Effect of EGR, DPF and DOC on BTE of DEE fuelled engine

\section{Smoke Emissions}

Figure 8 shows the effect of EGR, DPF and DOC on Smoke emissions. The engine powered with 20\% DEE without EGR had smoke emission of 50 HSU and it reduced to 13 HSU with DPF and further to $12 \mathrm{HSU}$ with DOC. i.e, reduction in smoke emission by DPF was about $75 \%$ and by DOC by $7 \%$.

\section{HC Emissions}

The variation of $\mathrm{HC}$ emissions at different loads when the engine is supplied with $0 \%, 5 \%, 10 \%, 15 \%$ and $20 \%$ DEE is as shown in Figure 9. The HC emissions of the engine is decreased with increase in DEE ratio due to the oxygenated additives blends provided better and normal combustion. At $80 \%$ load, the HC emission was found to be $66 \mathrm{ppm}$ and $42 \mathrm{ppm}$ for $0 \%$ and 20\% DEE respectively. The variation of $\mathrm{HC}$ emission of diesel engine using 
Speed: $1500 \mathrm{rpm}, \mathrm{IT}: 23^{\circ} \mathrm{BTDC}$, IP: $220 \mathrm{bar}$,

CR: 17.5, Fuel: Diesel+Different \%DEE

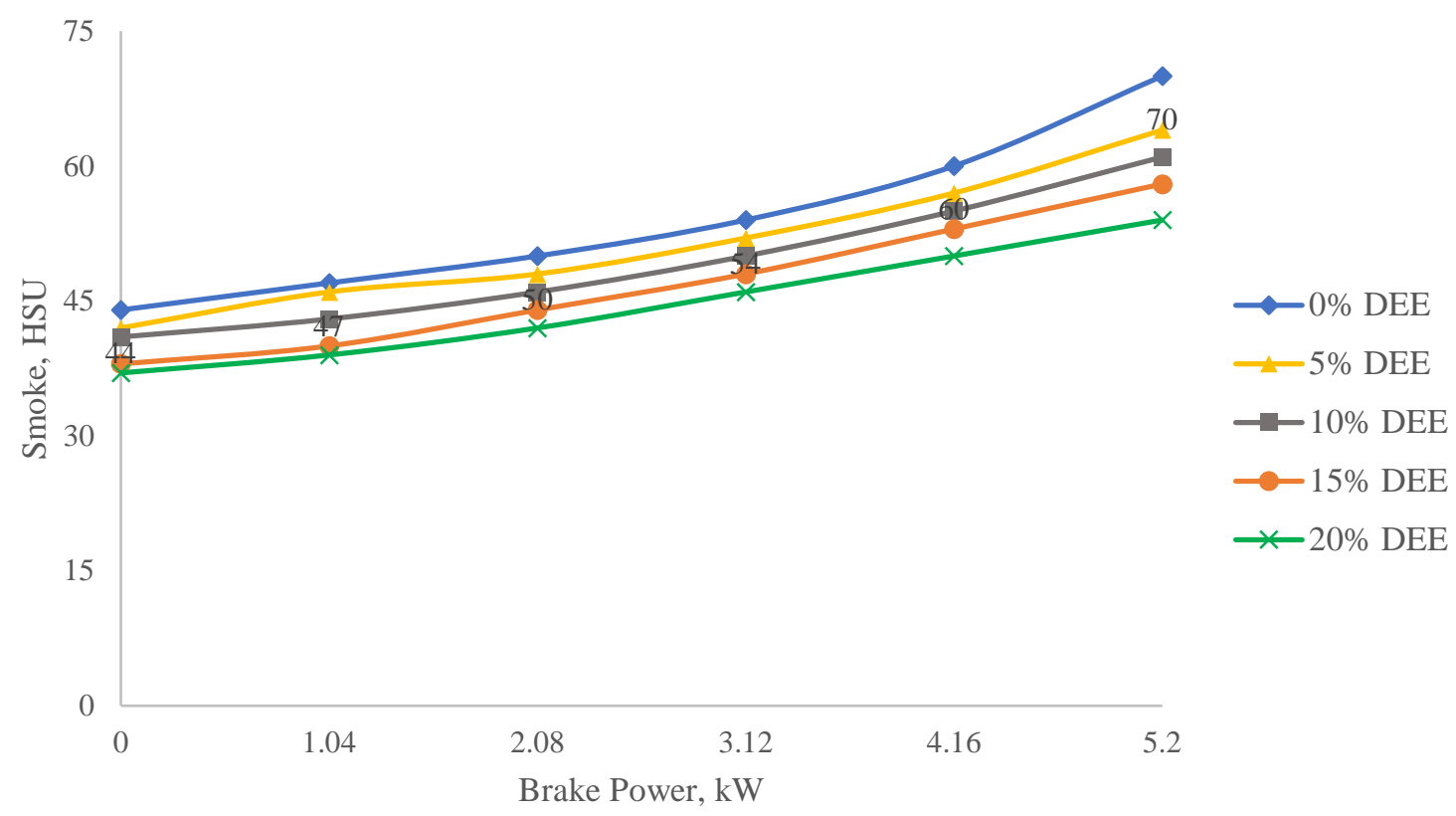

Figure 7. Effect of DEE on Smoke emissions

Speed: $1500 \mathrm{rpm}, \mathrm{IT}: 23^{\circ}$ BTDC, IP: 205 bar,

CR: 17.5, Fuel: 20\% DEE

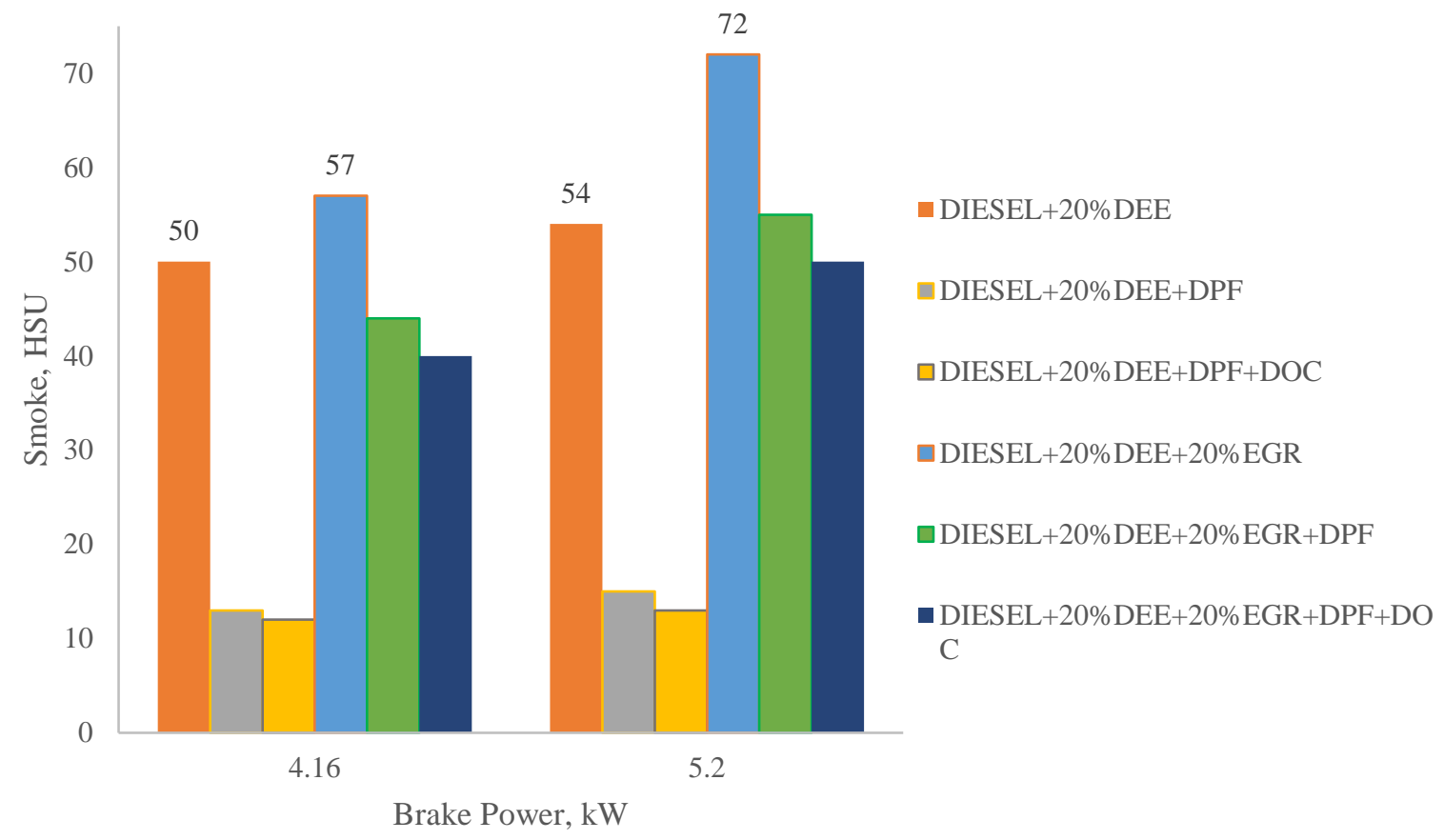

Figure 8. Effect of EGR, DPF and DOC on Smoke Emissions of DEE fuelled engine with 20\% EGR

DPF and DOC is shown in Figure 10. The HC emissions of the engine increased with EGR for both the loads. At $80 \%$ load, with $20 \%$ EGR, HC reduced by $40 \%$ adopting DPF and by $10 \%$ adopting DOC respectively.

\section{CO Emissions}

The variation of $\mathrm{CO}$ emissions at different loads when the engine is supplied with $0 \%, 5 \%, 10 \%, 15 \%$ and $20 \%$ DEE is as shown in Figure 11. The CO emission has decreased with increase in DEE blends. This reduction benefit is due to the presence of oxygen content in the DEE which enables better combustion and formation of 
Speed: $1500 \mathrm{rpm}$, IT: 23 BTDC, IP: 205 bar,

CR: 17.5, Fuel: Diesel+ Different \% DEE

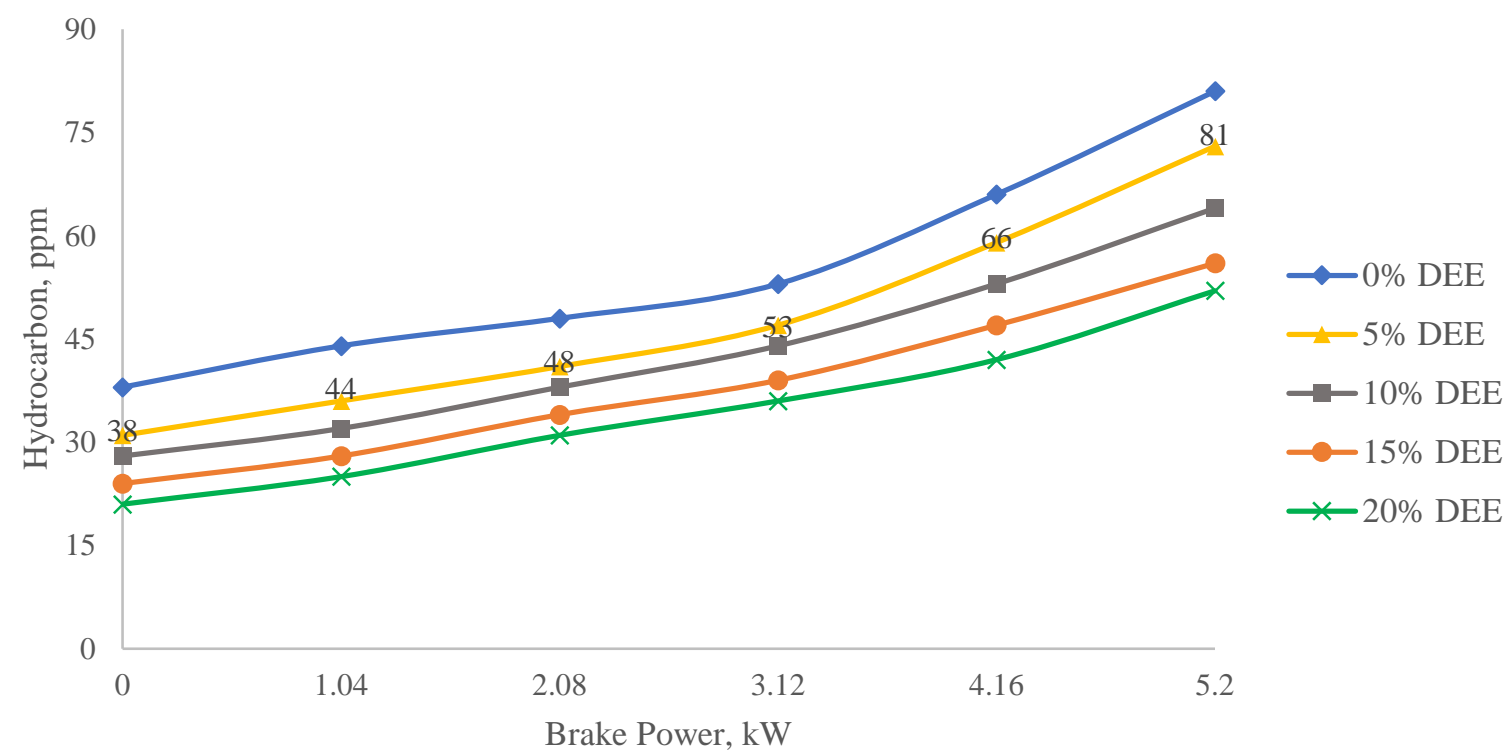

Figure 9. Effect of DEE on HC emissions

Speed: $1500 \mathrm{rpm}$, IT: 23 BTDC, IP: 205 bar, CR: 17.5, Fuel: 20\% DEE

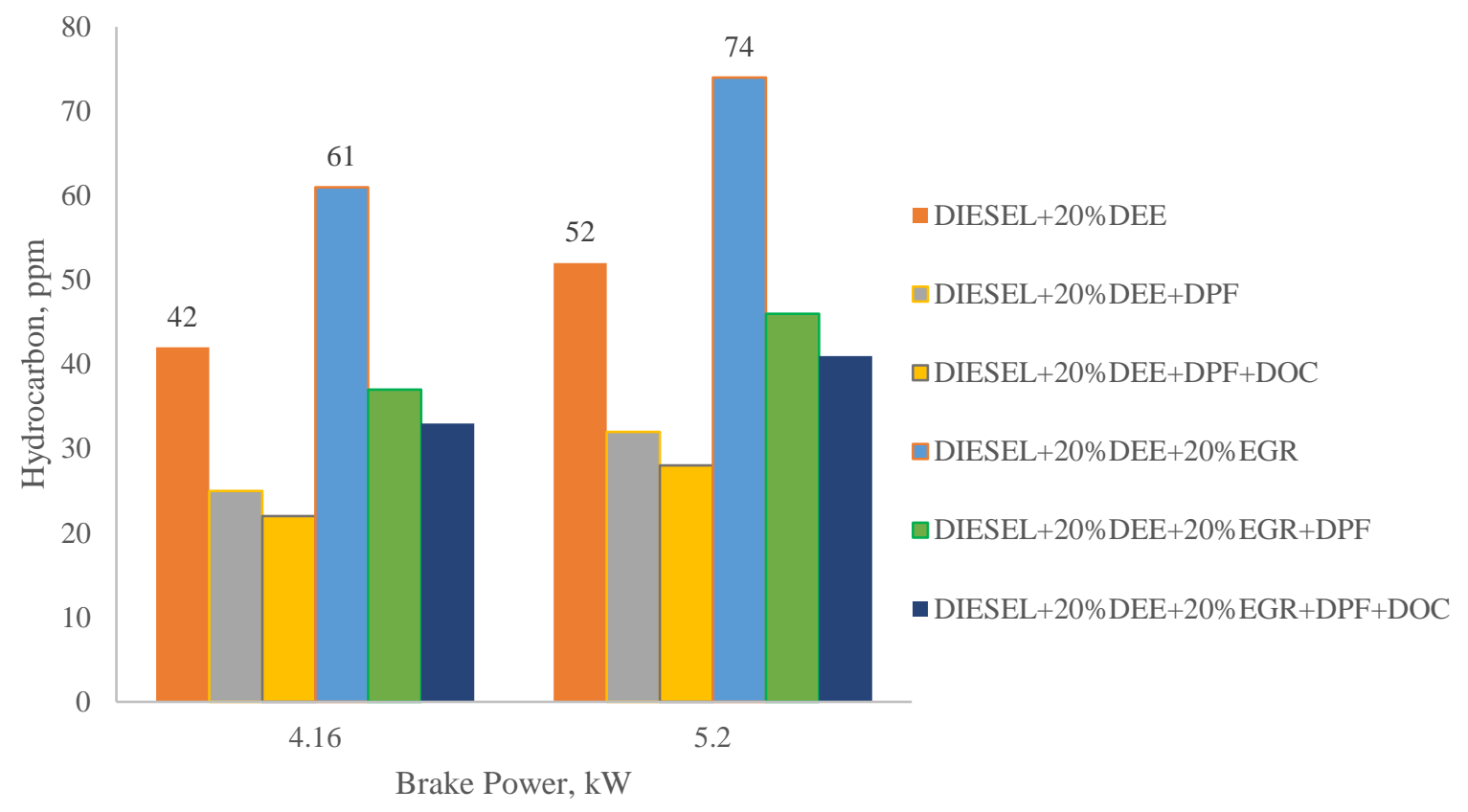

Figure 10. Effect of EGR, DPF and DOC on HC of DEE fuelled engine with $20 \%$ EGR

$\mathrm{CO}$ is less. Higher cetane number also could be the reason for lower CO. At $80 \%$ load, the CO emission was found to be $0.3 \%$ volume and $0.16 \%$ volume for $0 \%$ and $20 \%$ DEE respectively.

CO emissions for two loads when the engine is powered with 20\% DEE, 20\% EGR, DPF and DOC respectively as shown in Figure 12. CO emission increased when using DPF by $8 \%$ by volume. However, CO emission decreased with DOC further by $45 \%$ by volume. Hence, utilizing only DPF is not advisable and combination of both DPF \& DOC is essential for such engine operation.

\section{NOx Emissions}

The variation of NOx emissions at different loads when the engine is supplied with $0 \%, 5 \%, 10 \%, 15 \%$ and $20 \%$ DEE is as shown in Figure 13. The NOx emission has increased by injecting DEE. The formation of NOx is primarily a function of flame temperature, the residence time at that temperature, and the availability of oxygen 
Speed: $1500 \mathrm{rpm}, \mathrm{IT}: 23^{\circ}$ BTDC, IP: 205 bar

CR: 17.5, Fuel: Diesel+ Different \% DEE

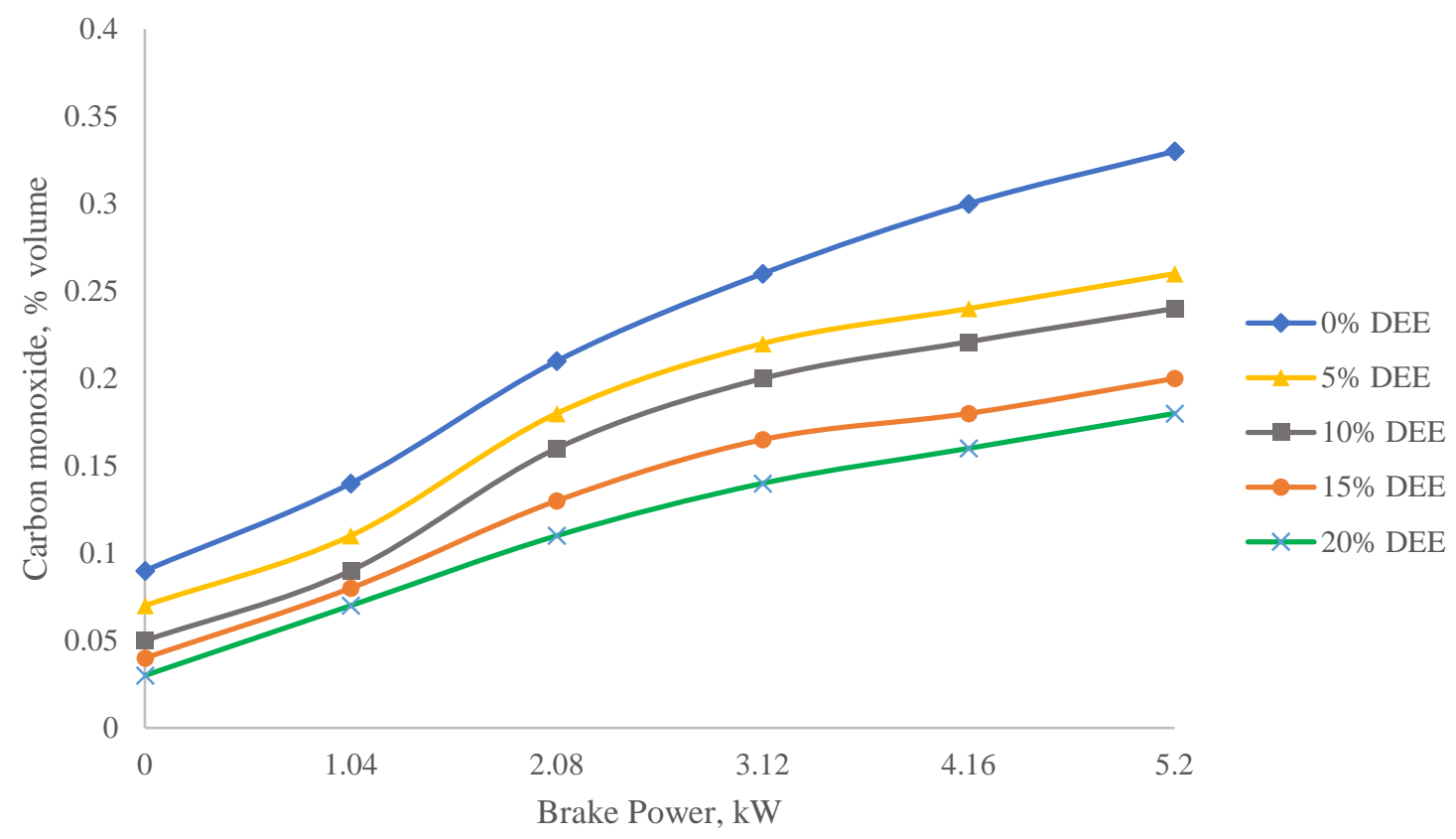

Figure 11. Effect of DEE on CO emissions

Speed: $1500 \mathrm{rpm}$, IT: $23^{\circ}$ BTDC, IP: 205 bar,

CR: 17.5 , Fuel: $20 \%$ DEE

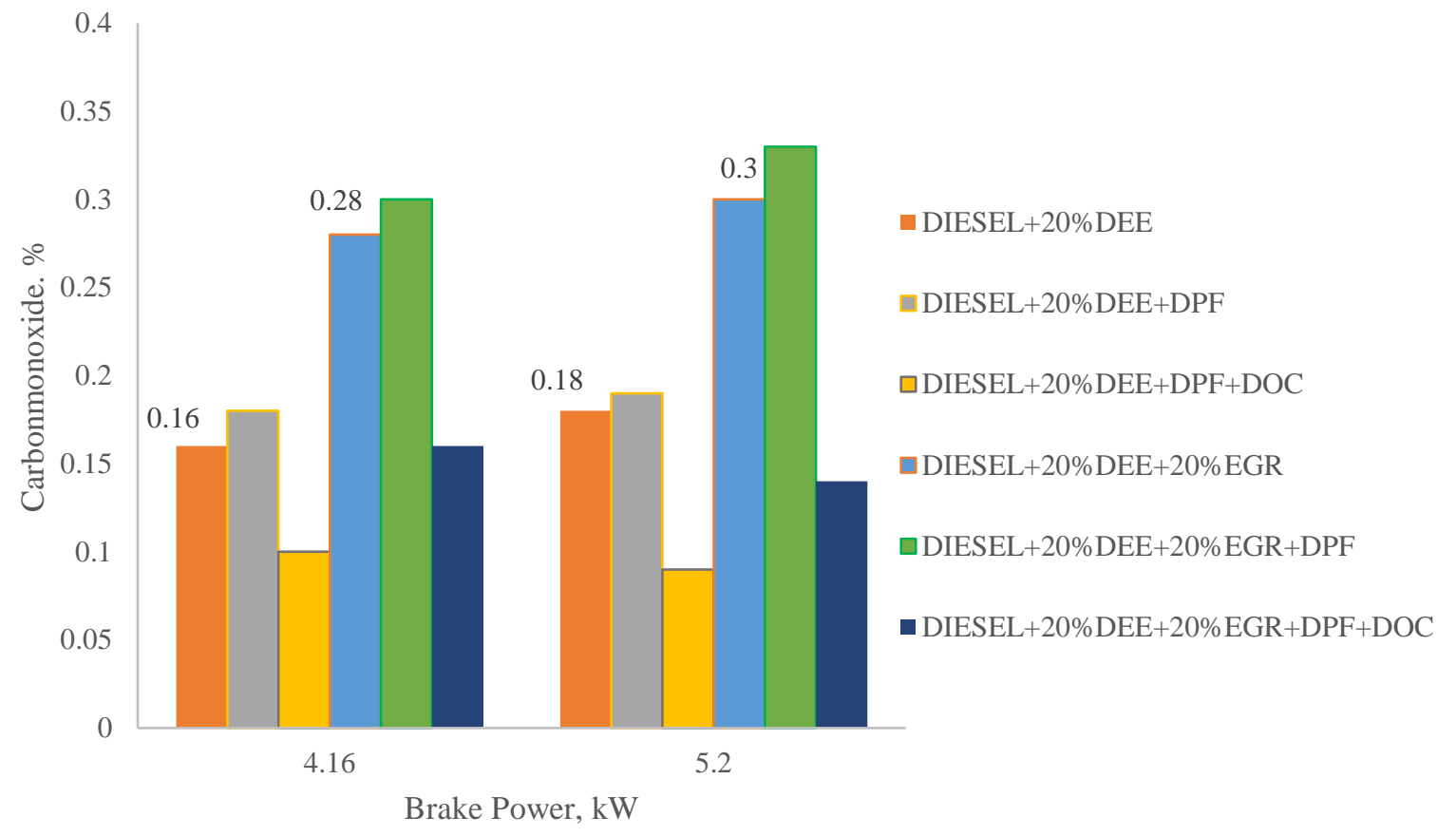

Figure 12. Effect of EGR, DPF and DOC on CO of DEE fuelled engine with 20\% EGR

in combustion chamber. More oxygen content in the DEE and higher cetane number, enhances the combustion process leading to increased combustion temperature there by increase in NOx emission. At $80 \%$ load, the NOx emission was found to be $840 \mathrm{ppm}$ and $977 \mathrm{ppm}$ for $0 \%$ and 20\% DEE respectively.

Variation of NOx emissions for two loads when the engine provided with 20\% DEE, DPF and DOC respectively as shown in Figure 14. NOx emission reduced by both DPF and DOC combinations. With DEE injection, NOx emissions have increased, hence EGR was essential to further reduce it. It is observed that, adopting DPF, NOx emission reduced by 10\%; adopting DOC, NOx emission further reduced by $6 \%$. Similar reduction percentage by DPF and DOC was observed when the engine was fuelled with neat diesel. 
Speed: $1500 \mathrm{rpm}$, IT: $23^{\circ}$ BTDC, IP: 220 bar

CR: 17.5, Fuel: Diesel+ Different \% DEE

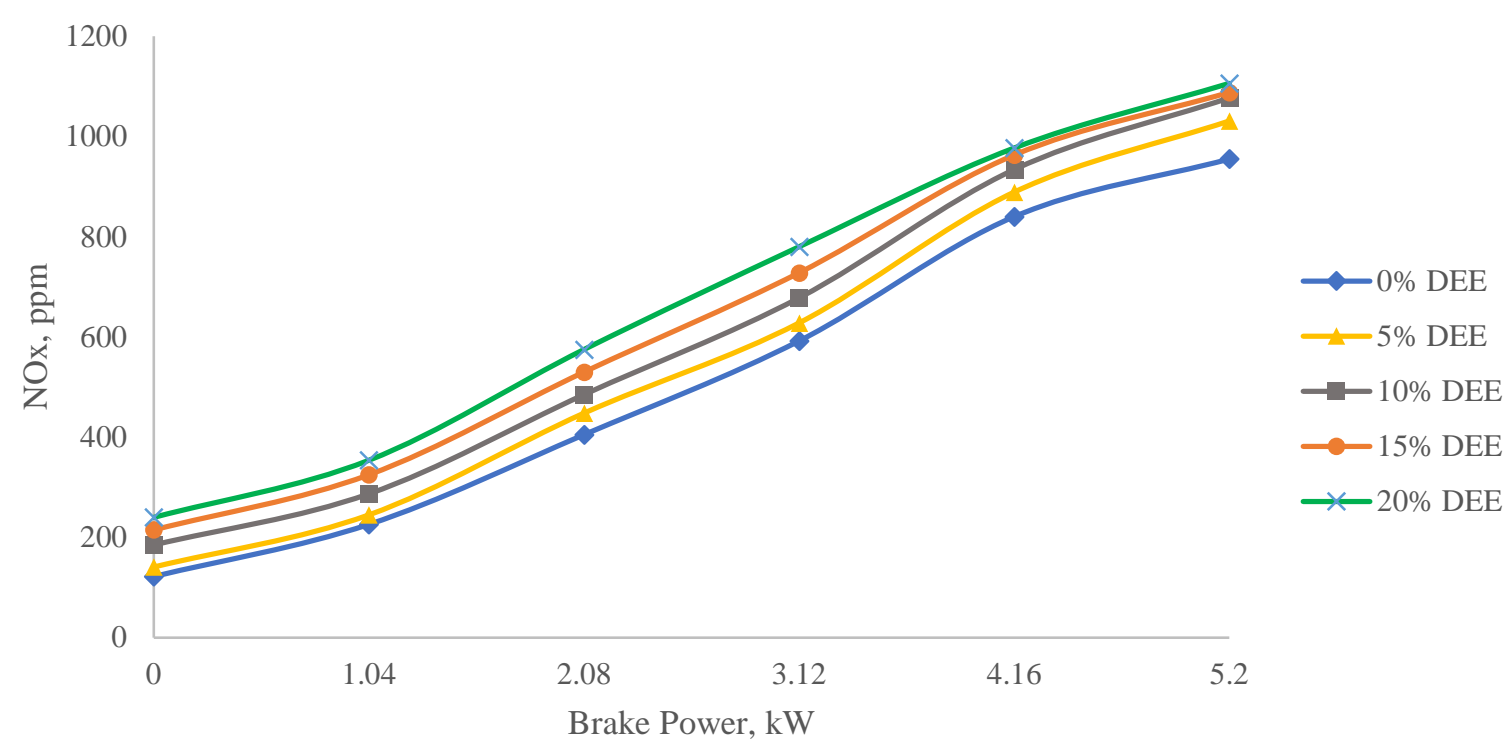

Figure 13. Effect of DEE on NOx emissions

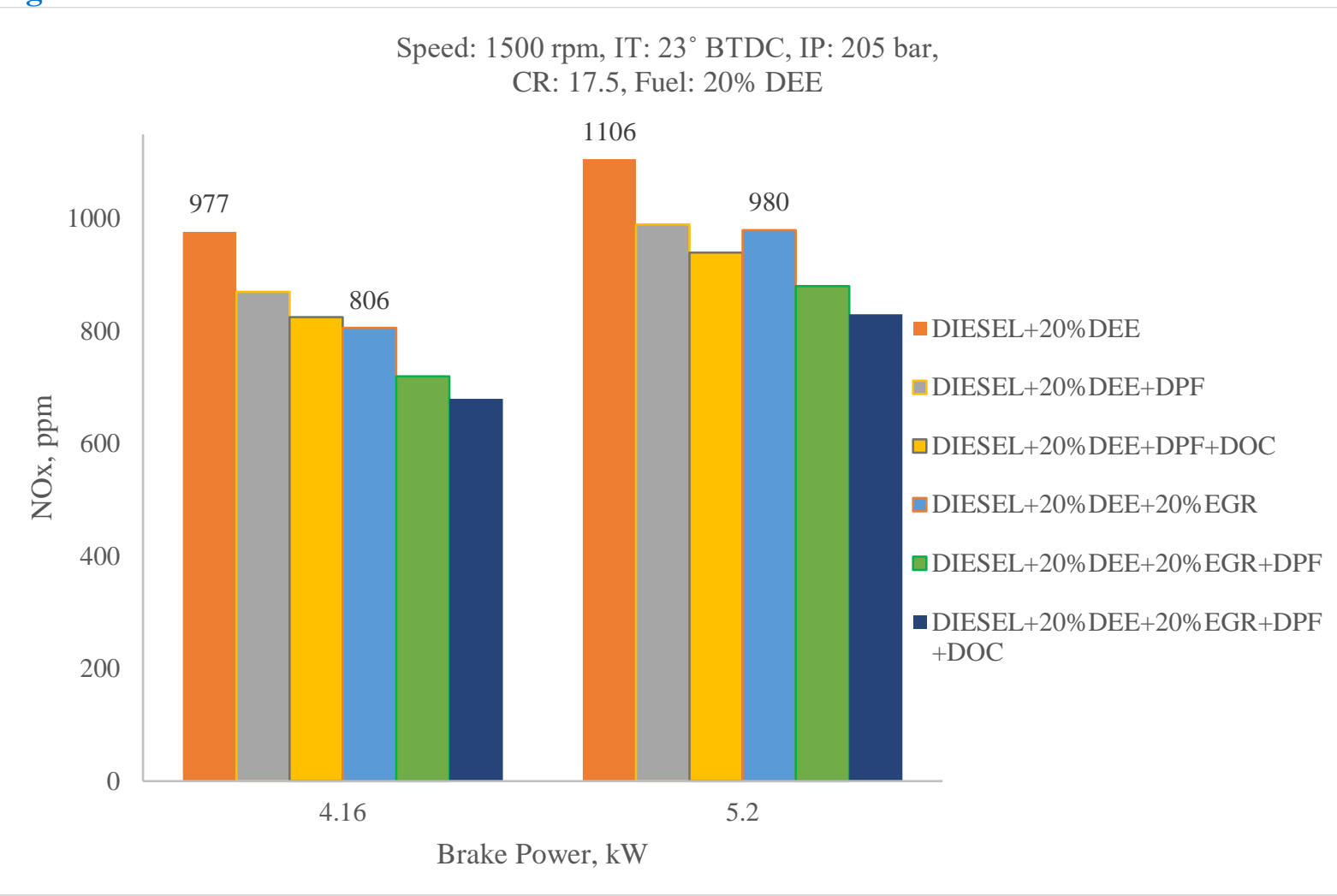

Figure 14. Effect of EGR, DPF and DOC on NOx Emissions of DEE fuelled engine with 20\% EGR

\section{Combustion Characteristics}

In this section, different combustion parameters at load conditions are presented in the form of graphs. The results are analyzed, discussed and compared with diesel fuel operation.

\section{Peak Pressure}

Figure 15 shows the variation of peak pressure with brake power for $0 \%, 5 \%, 10 \%, 15 \%$ and $20 \%$ DEE. The peak pressure has increased with increase in load for all DEE blends. The peak pressure is found to be highest for $20 \%$ DEE blend. This increase in cylinder pressure results in higher power output. This could be on account of 
Speed: $1500 \mathrm{rpm}, \mathrm{IT}: 23^{\circ}$ BTDC, IP: 205 bar,

CR: 17.5, Fuel: Diesel+Different \% DEE

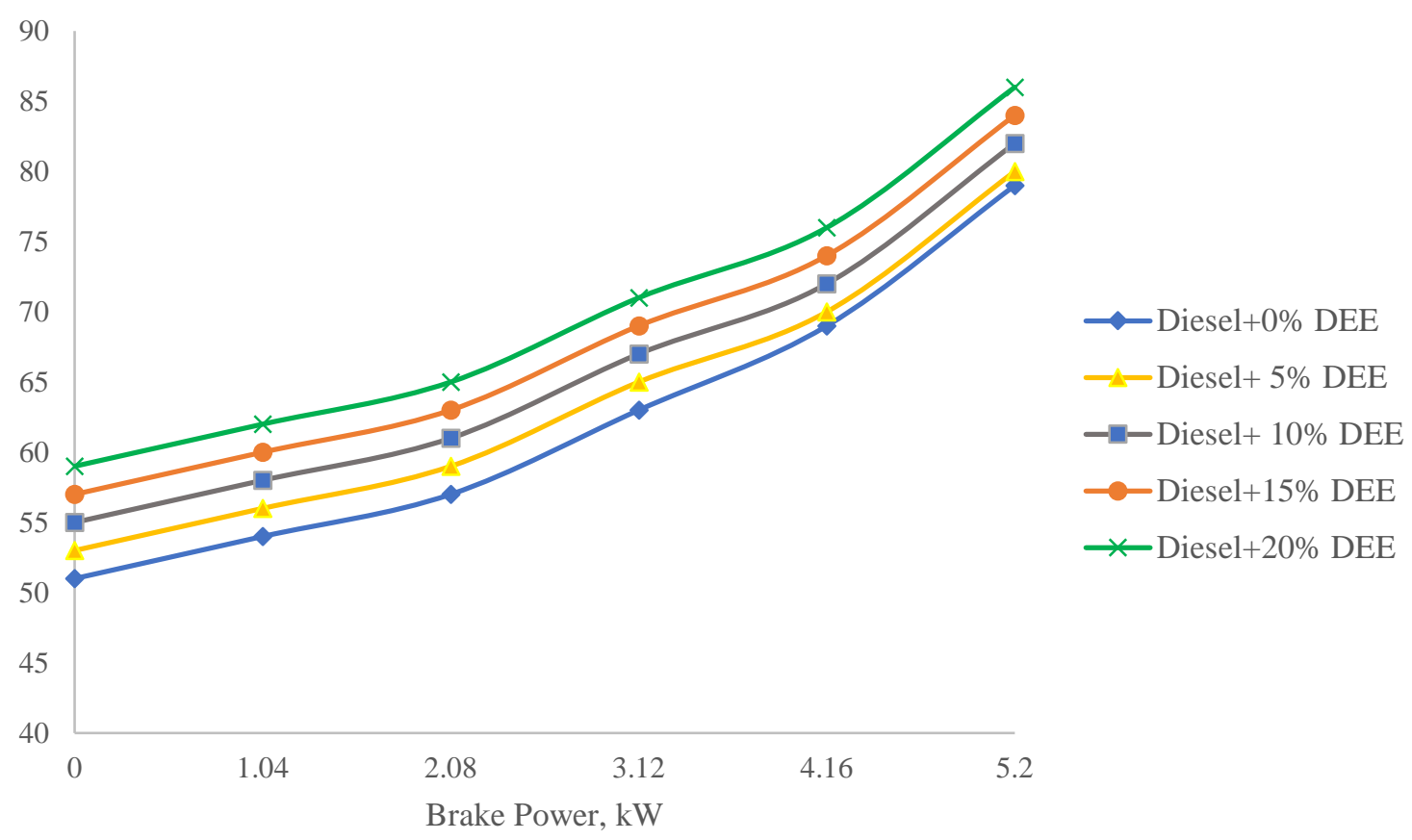

Figure 15. Effect of DEE on Peak Pressure

Speed: $1500 \mathrm{rpm}, \mathrm{IT}: 23^{\circ}$ BTDC, IP: 205 bar,

CR: 17.5, Fuel: Diesel+Different \% DEE

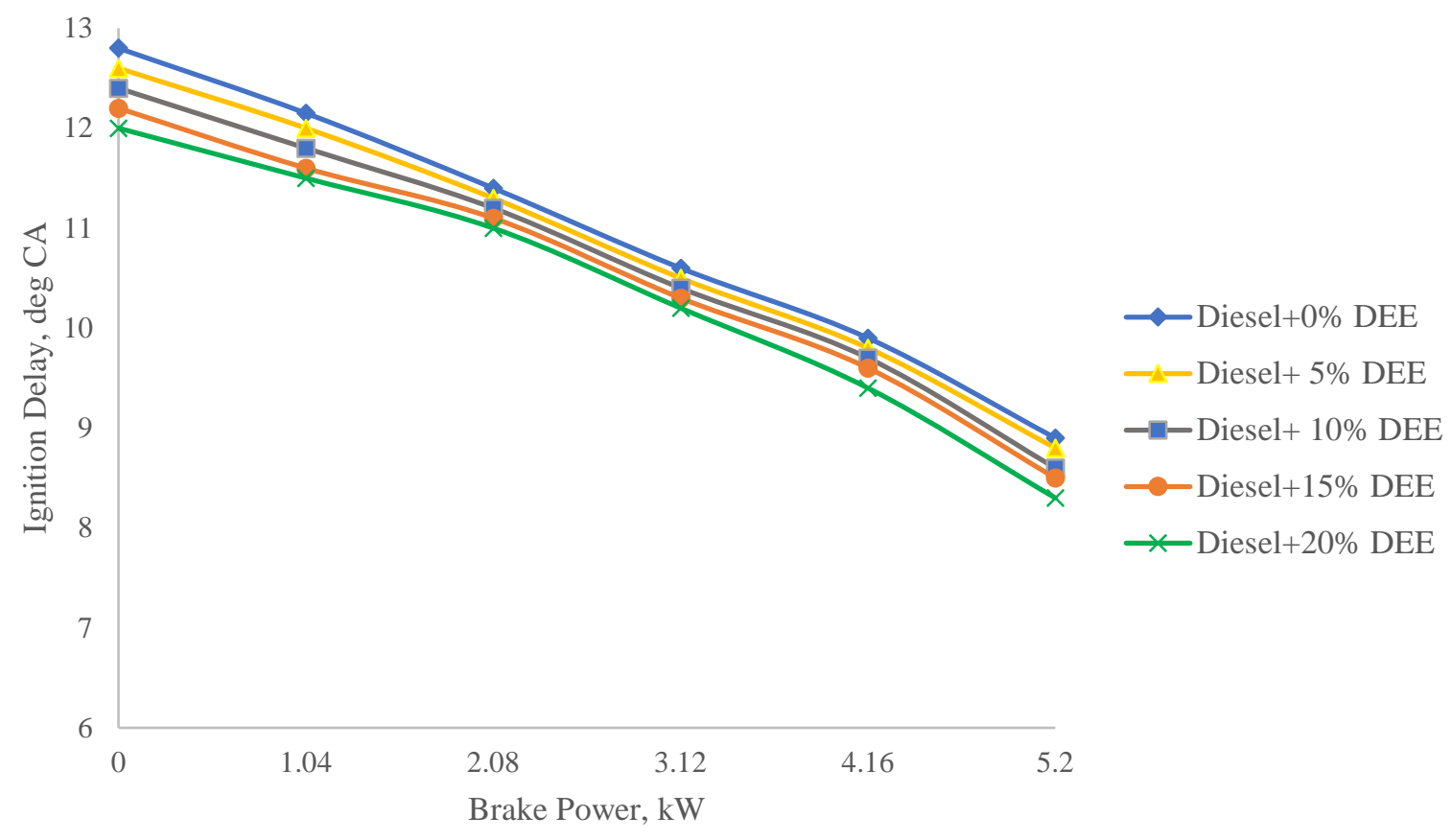

Figure 16. Effect of DEE on Ignition Delay

faster combustion due to more oxygen present and higher cetane number of DEE. The highest peak pressure is found to be 76 bar for $20 \% \mathrm{DEE}$ operation at $80 \%$ load.

\section{Ignition Delay}

Figure 16 shows the variation of ignition delay with Brake power for $0 \%, 5 \%, 10 \%, 15 \%$ and 20\% DEE. Based on heat release rate graph, the ignition delay has decreased with addition of DEE. According to the in-cylinder pressure and heat release profiles, combustion starts with lesser delay for all of diethyl ether blends with baseline 
Speed: $1500 \mathrm{rpm}, \mathrm{IT}: 23^{\circ}$ BTDC, IP: 205 bar,

CR: 17.5, Fuel: Diesel+Different \% DEE

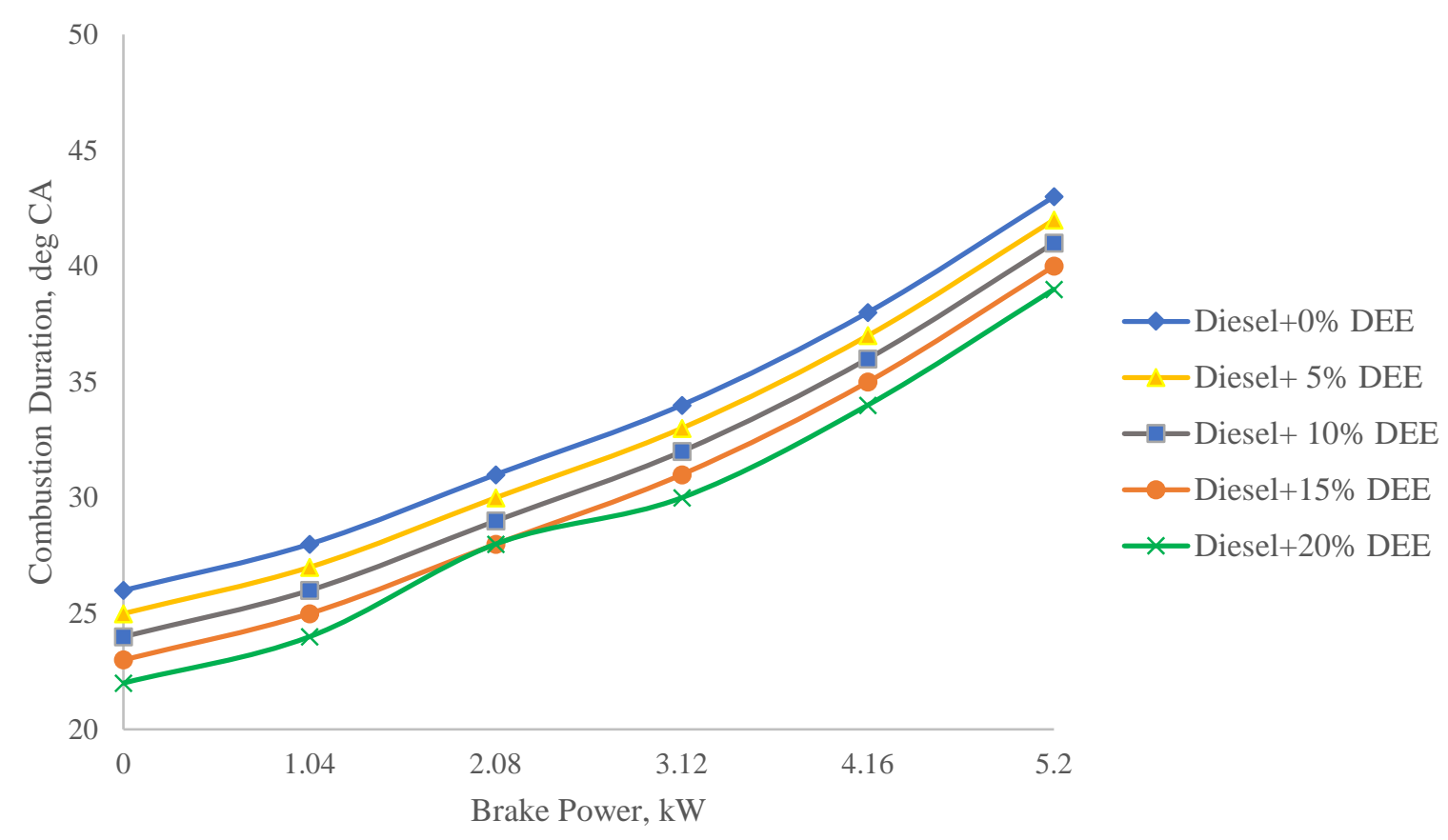

Figure 17. Effect of DEE on Combustion Duration

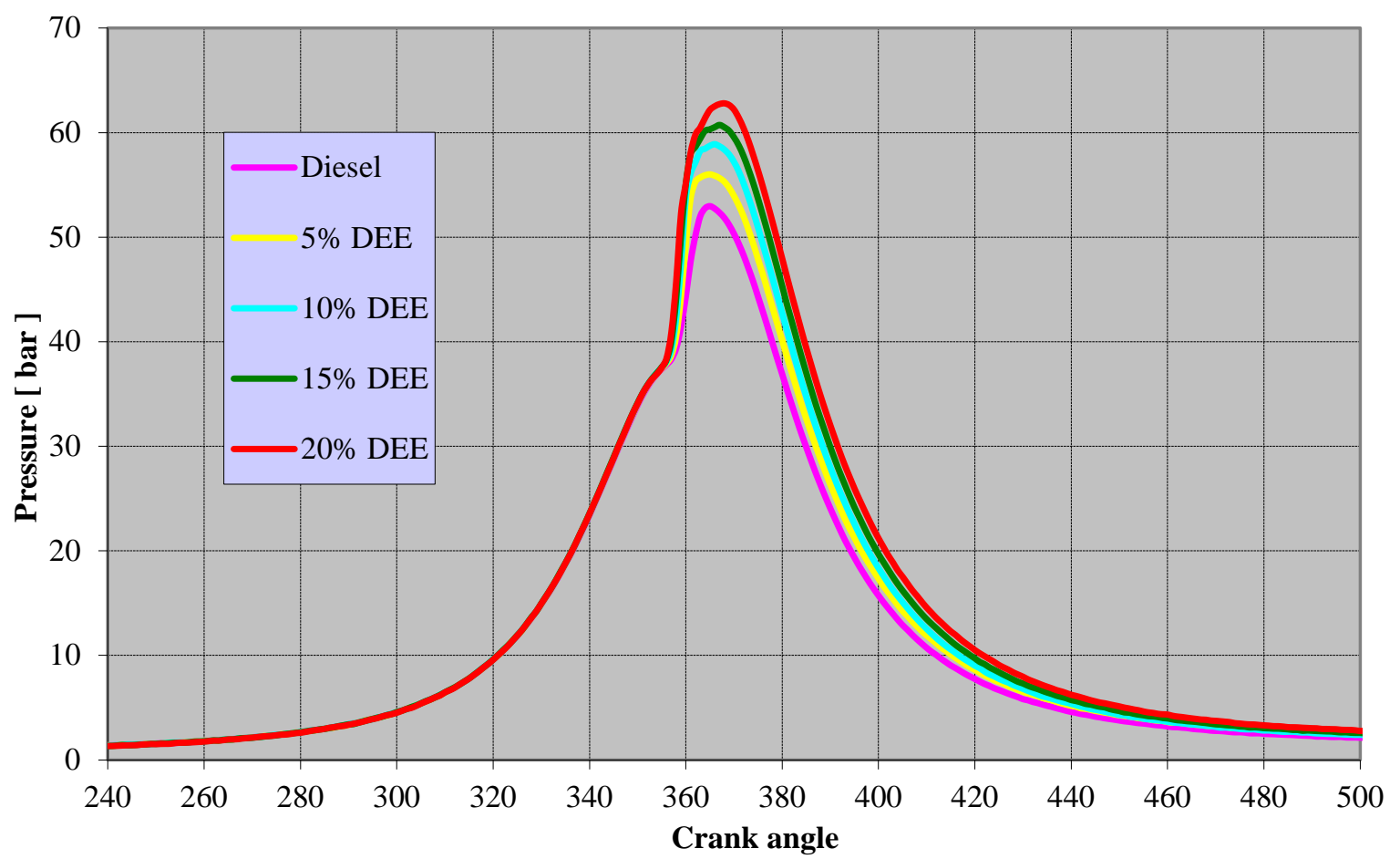

Figure 18. Variation of pressure with crank angle for different DEE ratios

fuel and it becomes lesser prominent with higher diethyl ether blends. With increase in load, air-fuel ratio decreases, operating temperature increases and hence, delay period decreases.

At $80 \%$ load, the delay period observed as $9.9 \mathrm{deg}$ CA and $9.4 \mathrm{deg}$ CA for neat diesel and Diesel $+20 \%$ DEE respectively.

\section{Combustion Duration}

Figure 17 shows the variation of combustion duration with brake power for different DEE blends. The duration of combustion has decreased with increase in DEE blends. The reason could be faster combustion due to higher cetane number. At $80 \%$ load, the combustion duration is 38 deg CA and 34 deg CA for neat diesel and 


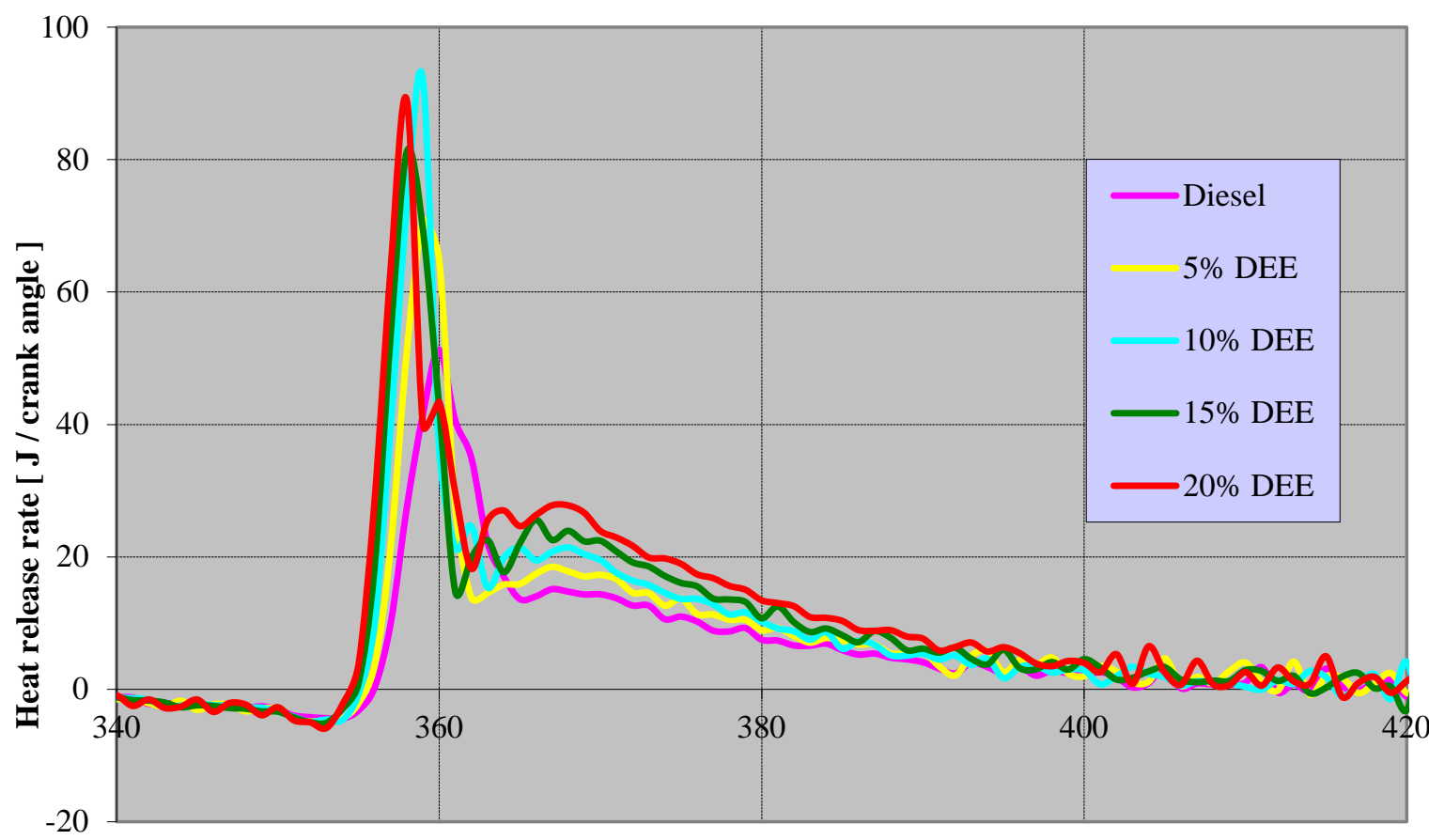

\section{Crank angle}

Figure 19. Variation of heat release rate with crank angle for different DEE ratios

Table 3. The performance and emission values at optimum conditions

\begin{tabular}{ll}
\hline Load & $80 \%$ Full load \\
\hline Brake Power & $4.16 \mathrm{~kW}$ \\
\hline Brake thermal efficiency & $27.5 \%$ \\
\hline Peak pressure & $69 \mathrm{bar}$ \\
\hline Ignition delay & $10.2 \mathrm{deg} \mathrm{CA}$ \\
\hline Combustion duration & $44 \mathrm{deg} \mathrm{CA}$ \\
\hline Smoke emissions & $11 \mathrm{HSU}$ \\
\hline Hydrocarbon emissions (HC) & $33 \mathrm{ppm}$ \\
\hline Carbon monoxide emissions (CO) & $0.16 \%$ \\
\hline Nitrogen oxide (NOx) & $680 \mathrm{ppm}$ \\
\hline
\end{tabular}

Diesel $+20 \%$ DEE condition. The combustion duration observed with DEE was significantly shorter than that of diesel. This could be due to lower auto ignition temperature and higher cetane number of DEE.

\section{Cylinder Pressure}

The cylinder pressure - crank angle history was acquired for 100 cycles and the averaged pressure variation with crank angle at $80 \%$ load when diesel injected at $0 \%, 5 \%, 10 \%, 15 \%, 20 \%$ DEE blended with diesel is shown in Figure 18. The mixture formation during delay period and extent of ignition delay period regulates uncontrolled combustion phase. This mixture preparation during the ignition delay period is responsible for the variations of peak pressure and maximum rate of pressure rise.

According to in-cylinder pressure and heat release profiles, combustion starts with delay for all of diethyl ether blends with baseline diesel fuel and it becomes more prominent with higher diethyl ether blends.

\section{Heat Release Rate}

Figure 19 shows the variation of heat release rate for diesel injected with $0 \%, 5 \%, 10 \%, 15 \%, 20 \%$ DEE blended with diesel respectively

The performance and emission values at these conditions are mentioned in Table 3.

\section{CONCLUSIONS}

The single cylinder diesel engine was operated on diesel with diethyl ether in blended form with and without EGR and having DPF \& DOC. It is observed that the engine was consistent in its operation throughout the experimental investigations when operated on selected fuel combination. 
Based on the comprehensive experimental investigations carried out the following conclusions have been derived.

$>$ BTE is found to be increasing by injecting the diethyl ether. The reason is that di-ethyl ether which is added as an additive supply as an extra oxygen molecule to the fuel for burning.

D The highest BTE was found to $29.25 \%$ for $80 \%$ load condition using $20 \%$ DEE and without exhaust gas recirculation.

$>$ The HC emissions of the engine is increased with increase in DEE ratio due to the oxygenated additives blends provided better and normal combustion.

$>$ At $80 \%$ load, the CO emission was found to be $0.3 \%$ and $0.16 \%$ for $0 \%$ and $20 \%$ DEE respectively.

$>$ Since more oxygen content in the DEE, there is increase in NOx emmission. At $80 \%$ load, the NOx emission was found to be $840 \mathrm{ppm}$ and $977 \mathrm{ppm}$ for $0 \%$ and 20\% DEE respectively.

$>$ The peak pressure has increased with increase in load for all DEE blends.

> According to the in-cylinder pressure and heat release profiles, combustion starts with lesser delay for all of diethyl ether blends with baseline fuel and it becomes lesser prominent with higher diethyl ether blends.

D The combustion duration observed with DEE was significantly shorter than that of diesel. This could be due to lower auto ignition temperature and higher cetane number of DEE.

D The efficiency reduced when exhaust gas is introduced into the intake. This happens due to burnt gas occupying the engine cylinder which thereby reduces the availability of oxygen for combustion.

$>$ At $80 \%$ load, $20 \%$ DEE blend and $20 \%$ EGR, the efficiency obtained is $27.5 \%$.

$>$ The increase in smoke was observed with increase in EGR for all operating conditions. The HC value of $61 \mathrm{ppm}$ were obtained when the diesel engine is injected with 20\% DEE and having 20\% EGR at 80\% load

$>$ The $\mathrm{CO}$ emission has decreased with increase in DEE/ diesel blends. It's a indication that the combustion in better with the addition of DEE.

$>$ The NOx emission has decreased with increase in EGR rates. This reduction is predominant when the diesel engine is operating with $20 \%$ DEE ratio.

$>$ For the engine having $20 \%$ DEE fuel, smoke emissions reduced by at least $75 \%$ by having DPF. Having DPF, HC emission reduced from $42 \mathrm{ppm}$ to $26 \mathrm{ppm}$. With DOC, emission reduced from $26 \mathrm{ppm}$ to 22 ppm.

D The CO emission has increased with using DPF by 15\%. However, CO emission decreased with DOC oxidises by $45 \%$.

$>$ It is observed that, adopting DPF, NOx emission reduced by 10\%; adopting DOC, NOx emission reduced by $6 \%$.

Overall the optimum engine operating condition is found to be DEE of 20\% with 20\% EGR when both DPF and DOC were adopted.

\section{ACKNOWLEDGEMENTS}

The authors would like to thank the Research Centre, Department of Mechanical Engineering, Acharya Institute of Technology, Bangalore for their continuous help.

\section{REFERENCES}

Agrawal, A. K., Singh, S. K., Sinha, S. and Shukla, M. K. (2004). Effect of EGR on the exhaust gas temperature and exhaust opacity in compression ignition engines. Sadhana, 29(3), 275-284. https://doi.org/10.1007/BF02703777

Chatterjee, S., Canway, R., Viswanathan, S., Blomquist, M., Klusener, B. and Andersson, S. (2003). NOx and PM Control from Heavy Duty Diesel Engines Using a Combination of Low Pressure EGR and Continuously Regenerating Diesel Particulate Filter. SAE, Paper 2003-01-0048. https://doi.org/10.4271/2003-01-0048

Hayes, T. K., Savage, L. D. and Soreson S. C. (1986). Cylinder Pressure Data Acquisition and Heat Release Analysis on a Personal Computer. Society of Automotive Engineers, Paper No. 860029, USA.1986. https://doi.org/10.4271/860029

Hohenberg, G. F. (1979). Advanced approaches for heat transfer calculations. Society of Automotive Engineers, Paper No. 790825. https://doi.org/10.4271/790825

Kouremenos, D. A., Hountalas, D. T. and Binder, K. B. (2001). The Effect of EGR on the Performance and Pollutant Emissions of Heavy Duty Diesel Engines Using Cinstant and Variable AFR. SAE, Paper 2001-010198. 
Mallikarjun, M. V., Mamilla, V. R. and Rao, G. L. N. (2013). NO x Emission Control Techniques when CI Engine is Fueled with Blends of Mahua Methyle Esters and Diesel. Int J Eng Sci Emerg Technology, 4(2), 96-104.

Miyamoto, N., Ogawa, H., Nurun, N. M., Obata, K. and Arima, T. (1997). Smokeless, Low NOx, High Thermal Efficiency, and Low Noise Diesel Combustion with Oxygenated Agents as Main Fuel. SAE, Paper 980506.

Nakatani, K., Hirota, S., Takeshima, S., Itoh, K., Tanaka, T. and Dohmae, K. (2002). Simultaneous PM and NOx Reduction System for Diesel Engines. SAE, Paper 2002-01-0957. https://doi.org/10.4271/2002-01-0957 